\title{
Comparison of the etiological causes in patients under and/or over the age of 65 admitted to the emergency department with non-traumatic chest pain
}

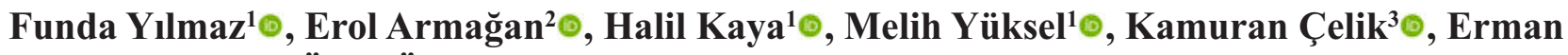 \\ Uygun $^{4} \odot$, Havva Özge Özkan Yıldız ${ }^{5}$, Sibel Gafuroğulları ${ }^{3} \odot$
}

\begin{abstract}
${ }^{1}$ Department of Emergency Medicine, University of Health Sciences, Bursa Yüksek Ihtisas Training and Research Hospital, Bursa, Turkey

${ }^{2}$ Department of Emergency Medicine, Bursa Uludağ University School of Medicine, Bursa, Turkey

${ }^{3}$ Department of Emergency Medicine, Büyükçekmece Mimar Sinan State Hospital, İstanbul, Turkey

${ }^{4}$ Department of Emergency Medicine, Bursa Gemlik Muammer A ̌̆ım State Hospital, Bursa, Turkey

${ }^{5}$ Department of Emergency Medicine, Ballkesir State Hospital, Balıkesir, Turkey
\end{abstract}

\section{ABSTRACT}

Objectives: One of the most common reasons for admission to the emergency department is chest pain. The clinical presentation of chest pain is quite wide. The study aimed to compare the diagnoses of patients under and/or over the age of 65 admitted to the emergency department with non-traumatic chest pain.

Methods: A thousand patients admitted to the emergency department with non-traumatic chest pain between 15.10.2014 and 15.07. 2015 were included in the study. Patients were divided into two groups according to age group as $<65$ years old and $\geq 65$ years old. Age, gender, the type of admission, comorbidities, accompanying symptoms, diagnosis, outcome and hospitalization were recorded.

Results: Five hundred eighteen males and 482 females were included in the study. Eight hundred nineteen patients were between the ages of 18 to 64 . The most common accompanying symptom was dyspnea in both age groups. Hypertension was the most common concomitant disease in the 18-64 year age group while coronary artery disease was the most common diseasein the 65 and over age group.

Conclusions: Non-cardiac chest pain is more common in the young population admitted to the emergency department while life-threatening chest pain is more common in the population over the age of 65 .

Keywords: Chest pain, emergency department, acute coronary syndrome, coronary artery disease

$\mathrm{O}$ ne of the most common reasons for admission to the emergency department is chest pain. It is a common clinical symptom that may be due to various causes such as acute myocardial infarction (AMI) or a benign cause such as thoracic muscle pain $[1,2]$. Chest pain is one of the reasons that cause anxiety in patients and therefore causes frequent admissions to the emergency department. Anamnesis and physical examination are very important in chest pain. With a good anamnesis and physical examination, patientsdon'tundergo unnecessary procedures, so the time of diagnosis for the disease is shortened. Thus, mortality and morbidity rates can also be significantly reduced $[3,4]$.

Demographic characteristics, vital signs, examination findings, and physiological changes associated 
with aging are important in determining the causes of chest pain. The causes of chest pain are affected by many factors. One of the most important of these factors is age. The causes of chest pain differ in patients according to age (Above and under 65 years of age). Although patients under the age of 65 are admitted to the emergency department more frequently with chest pain, life-threatening chest pain is less common in those patients. Patients older than 65 are less commonly admitted to the emergency department with chest pain, but these patients have more serious diagnoses. Aging physiology leads to atypical signs and symptoms, pharmacodynamic changes, decrease in functional reserve, and social problems. This makes it difficult to determine the cause of chest pain in elderly patients in an emergency department. For this reason, it is often necessary to take anamnesis from the relatives of the patientwho knowhim very well.

The study aimed to compare the diagnoses of the patients underand/or over the age of 65 admitted to the emergency service with non-traumatic chest pain.

\section{METHODS}

Patients who were admitted to Bursa Yüksek İhtisas Training and Research Hospital Emergency Department with non-traumatic chest pain between 15.10.2014 and 15.07. 2015 were included in the study. Ethics committee approval was obtained for the study. Patients under the age of 18 and patients that exposed to trauma were excluded from the study. The study was a prospective study. A thousand patients were included. The data was recorded to the study form by the emergency medical assistant who evaluated the patients. The patients' names and surnames, date of admissions to the emergency department, hospital protocols, age, gender, the type ofadmissions, accompanying diseases, accompanying symptoms, diagnoses, outcomes, and hospitalizations were recorded in the study form.

Patients were divided into two groups according to age group as $<65$ years and $\geq 65$ years. Chest pains were divided into three groups as the chest wallinduced, pleuritic and visceral chest pain. Costochondritis, xifodynia, fibromyalgia were included in the chest wall-induced chest pain. Pulmonary embolism, pneumonia, spontaneous pneumothorax, pericarditis, and pleurisy were included in the pleuritic chest pain group. Typical effort angina, atypical angina, acute myocardial infarction, aortic dissection, esophageal reflux, and peptic ulcus were included in the visceral type chest pain group.

The types of admission were divided into two as outpatient or 112 (Emergency call number in Turkey). The methods of termination were hospitalization, discharge, referral, exitus in the emergency department and refusal of treatment. In our study, gender, ways of admission, comorbidities, accompanying symptoms, diagnoses and terminations were compared according to age groups.

\section{Statistical Analysis}

SPSS 21.0 software was used for statistical analysis of the data. Mean, standard deviation, median, lowest and highest frequency and ratio values were used in descriptive statistics of the data. The chisquare test was used to analyze qualitative data.

\section{RESULTS}

A thousand patients admitted to the emergency department with chest pain were included in the study. Five hundred eighteen males and 482 females were included in the study. Eight hindred nineteen patients were between the ages of 18 to 64 (Table 1).

Five hundred and seventy-six patients $(57.6 \%)$ had accompanying symptoms. The most common accompanying symptom was dyspnea in both age groups. In the study, $581(70.9 \%)$ of the patients in the 18-64 age group did not have any comorbidities, whereas $138(79.0 \%)$ in the 65 years and older group had comorbidities. Hypertension was the most common comorbidity in the 18-64 age group and

Table 1. Comparison of age groups and genders

\begin{tabular}{cccc}
\hline & $\begin{array}{c}\mathbf{1 8 - 6 4} \\
\text { years old }\end{array}$ & $\begin{array}{c}\geq \mathbf{6 5} \\
\text { years old }\end{array}$ & $\begin{array}{c}\boldsymbol{p} \\
\text { value* }^{*}\end{array}$ \\
\hline Gender, $\mathbf{n}(\%)$ & & & \\
Female & $408(49.8 \%)$ & $74(40.9 \%)$ & $\mathbf{0 . 0 3 0}$ \\
Male & $411(50.2 \%)$ & $107(59.1 \%)$ & $\mathbf{0 . 0 3 0}$ \\
\hline
\end{tabular}

Data are shown as n (\%). ${ }^{*}$ The chi-square test 
Table 2. Comparison of accompanying symptoms and comorbidities according to age groups

\begin{tabular}{|cccc}
\hline & $\mathbf{1 8 - 6 4}$ years old & $\geq \mathbf{6 5}$ years old & $\boldsymbol{p}$ value* \\
\hline Accompanying symptoms, n (\%) & & & \\
\hline No & $381(46.5 \%)$ & $43(23.8 \%)$ & $<\mathbf{0 . 0 0 1}$ \\
\hline Yes & $438(53.5 \%)$ & $138(76.2 \%)$ & \\
\hline Dyspnoea & $113(13.8 \%)$ & $57(31.5 \%)$ & \\
\hline Malaise & $59(7.2 \%)$ & $17(9.4 \%)$ & \\
\hline Tachycardia & $61(7.4 \%)$ & $7(3.9 \%)$ & \\
\hline Cough & $51(6.2 \%)$ & $12(6.6 \%)$ & \\
\hline Nausea & $45(5.5 \%)$ & $13(7.2 \%)$ & \\
\hline Other & $109(13.3 \%)$ & $32(17.6 \%)$ & \\
\hline Comorbidities, n (\%) & & & \\
\hline No & $581(70.9 \%)$ & $38(21.0 \%)$ & \\
\hline Yes & $238(29.1 \%)$ & $143(79.0 \%)$ & \\
\hline Hypertension & $70(8.5 \%)$ & $38(21.0 \%)$ & \\
\hline Coronary Artery Disease & $54(6.6 \%)$ & $45(24.9 \%)$ & \\
\hline Diabetes & $50(6.1 \%)$ & $27(14.9 \%)$ & \\
\hline COPD & $10(1.2 \%)$ & $11(6.1 \%)$ & \\
\hline Asthma & $10(1.2 \%)$ & $2(1.1 \%)$ & \\
\hline Psychiatric Diseases & $16(2.0 \%)$ & $0(0.0 \%)$ & \\
\hline Other & $28(3.5 \%)$ & $20(11.0 \%)$ & \\
\hline
\end{tabular}

Data are shown as n (\%). ${ }^{*}$ Chi-square test. COPD $=$ Chronic obstructive pulmonary disease

coronary artery diseasewas the most common comorbidity in the 65 and older age group (Table 2).

Visceral pain was the most common cause of pain in both age groups. It was found that $62.3 \%$ in the 18 64 age group and $77.9 \%$ in the patients over 65 had visceral pain. In the evaluation of acute chest pain type, atypical angina was found $29.5 \%$ in the $18-64$ age group and AMI was found as $31.5 \%$ in the group over 65 . The discharge rate was $84.7 \%$ in the $18-64$ age group, while the discharge rate was found to be $51.4 \%$ over 65 (Table 3 ).

Although the group over 65 were grouped as 65$74,75-84$ and over 85 , there was no statistically significant difference between the groups in terms of gender, type of hospital admission, comorbidities, cause of pain and the final status. (Table 4).

\section{DISCUSSION}

Chest pain is a common symptom that affects 20 to $40 \%$ of the general population throughout their lifetime [5]. It is estimated that the prevalence of chest pain in adults in the United States is 7.8 million cases annually, which accounts for $5.4 \%$ of all emergency visits throughout the country [6, 7]. In England and Wales, annual emergency service visits were reported to be 15 million and chest painaccounted for $2.4 \%$ of these visits [8].

In the hospital where the study was conducted, the emergency room visits were around 360 thousand cases annually and the prevalence of chest pain was $0.37 \%$. These rates were found to be less than the studies in the literature. The reason for that may be the presence of cardiology and chest diseases branch hospitals in a very close location to our hospital.

In a study, it was reported that $20-50 \%$ of the patients with chest pain were hospitalized and only 2$5 \%$ of these patients were diagnosed with the acute coronary syndrome (ACS) $[9,10]$. In our study, 20\% of the patient population was treated as inpatients. When we look at the subgroups, the hospitalization 
Table 3. Comparison of the types of chest pain according to age groups and distribution of end-forms of patients with age groups

\begin{tabular}{|c|c|c|c|}
\hline & 18-64 years old & $\geq 65$ years old & $p$ value* \\
\hline Diagnosis, n (\%) & & & $<0.001$ \\
\hline Chest Wall Pain & $236(28.8 \%)$ & $15(8.3 \%)$ & \\
\hline Pleuritic Pain & $73(8.9 \%)$ & $25(13.8 \%)$ & \\
\hline Visceral Pain & $510(62.3 \%)$ & $141(77.9 \%$ & \\
\hline \multicolumn{4}{|l|}{ Types of Acute Chest Pain } \\
\hline Atypical angina & $242(29.5 \%)$ & $44(24.3 \%)$ & \\
\hline Fibromyalgia & $209(25.5 \%)$ & $11(6.1 \%)$ & \\
\hline Acute myocardial infarction & $70(8.5 \%)$ & $57(31.5 \%)$ & \\
\hline Psychogenic causes & $101(12.3 \%)$ & $4(2.2 \%)$ & \\
\hline Pneumonia & $57(7.0 \%)$ & $20(11.0 \%)$ & \\
\hline Esophageal reflux & $47(5.7 \%)$ & $11(6.1 \%)$ & \\
\hline Typical exertional angina & $32(3.9 \%)$ & $17(9.4 \%)$ & \\
\hline Xiphodynia & $24(2.9 \%)$ & $2(1.1 \%)$ & \\
\hline Peptic ulcus & $12(1.5 \%)$ & $4(2.2 \%)$ & \\
\hline Pneumothorax & $11(1.3 \%)$ & $0(0.0 \%)$ & \\
\hline Costochondritis & $4(0.5 \%)$ & $2(1.1 \%)$ & \\
\hline Pleurisy & $3(0.4 \%)$ & $2(1.1 \%)$ & \\
\hline Pulmonary embolism & $2(0.2 \%)$ & $3(1.7 \%)$ & \\
\hline Aortic dissection & $3(0.4 \%)$ & $1(0.6 \%)$ & \\
\hline Aortic aneurysm & $1(0.1 \%)$ & $1(0.6 \%)$ & \\
\hline GIT perforation & $1(0.1 \%)$ & $0(0.0 \%)$ & \\
\hline Pancreatitis & $0(0.0 \%)$ & $1(0.6 \%)$ & \\
\hline Upper GIT bleeding & $0(0.0 \%)$ & $1(0.6 \%)$ & \\
\hline Result & & & $<0.001$ \\
\hline Discharged & $694(84.7 \%)$ & $93(51.4 \%)$ & \\
\hline Treatment Rejection & $6(0.7 \%)$ & $5(2.8 \%)$ & \\
\hline Exitus & $0(0.0 \%)$ & $2(1.1 \%)$ & \\
\hline Hospitalization & $119(14.5 \%)$ & $81(44.8 \%)$ & \\
\hline Coronary ICU Referral & $81(9.8 \%)$ & $59(32.6 \%)$ & \\
\hline Cardiology Hospitalization & $17(2.2 \%)$ & $10(5.6 \%)$ & \\
\hline Chest Surgery Hospitalization & $10(1.2 \%)$ & $0(0.0 \%)$ & \\
\hline Chest Diseases Hospitalization & $4(0.5 \%)$ & $7(3.8 \%)$ & \\
\hline Internal Medicine Hospitalization & $2(0.2 \%)$ & $3(1.6 \%)$ & \\
\hline Cardiovascular ICU Referral & $3(0.4 \%)$ & $0(0.0 \%)$ & \\
\hline General Surgery Hospitalization & $1(0.1 \%)$ & $1(0.6 \%)$ & \\
\hline Intensive Care Unit Referral & $1(0.1 \%)$ & $1(0.6 \%)$ & \\
\hline
\end{tabular}

Data are shown as $\mathrm{n}(\%) .{ }^{*} \mathrm{Chi}$-square test. GIT $=$ Gastrointestinal tract, ICU $=$ Intensive care unit 
Table 4. Comparison of gender, type of hospital admission, comorbidities, accompanying symptoms, diagnosis and results according to age groups

\begin{tabular}{|c|c|c|c|c|}
\hline & $65-74$ years & 75-84 years & $\geq 85$ years & $p$ value* \\
\hline Gender & & & & 0.706 \\
\hline Female & $38(43.7 \%)$ & $28(39.4 \%)$ & $8(34.8 \%)$ & \\
\hline Male & $49(56.3 \%)$ & $43(60.6 \%)$ & $15(65.2 \%)$ & \\
\hline Type of Admission & & & & 0.887 \\
\hline 112 & $15(17.2 \%)$ & $12(19.9 \%)$ & $3(13.0 \%)$ & \\
\hline Outpatient & $72(82.8 \%)$ & $59(83.1 \%)$ & $20(87.0 \%)$ & \\
\hline Comorbidities & & & & 0.451 \\
\hline Yes & $16(18.4 \%)$ & $15(21.1 \%)$ & $7(30.4 \%)$ & \\
\hline No & $71(81.6 \%)$ & $56(78.9 \%)$ & $16(30.4 \%)$ & \\
\hline Accompanying Symptom & & & & 0.591 \\
\hline No & $23(26.4 \%)$ & $14(19.7 \%)$ & $6(26.1 \%)$ & \\
\hline Yes & $64(73.6 \%)$ & $57(80.3 \%)$ & $17(73.9 \%)$ & \\
\hline Diagnosis & & & & 0.378 \\
\hline Chest Wall Pain & $9(10.3 \%)$ & $4(5.6 \%)$ & $2(8.7 \%)$ & \\
\hline Pleuritic Pain & $8(9.2 \%)$ & $12(16.9 \%)$ & $5(21.7 \%)$ & \\
\hline Visceral Pain & $70(80.5 \%)$ & $55(77.5 \%)$ & $16(69.6 \%)$ & \\
\hline Result & & & & 0.776 \\
\hline Discharged & $46(52.9 \%)$ & $38(53.5 \%)$ & $9(39.1 \%)$ & \\
\hline Treatment Rejection & $1(1.1 \%)$ & $2(2.8 \%)$ & $2(8.7 \%)$ & \\
\hline Exitus & $1(1.1 \%)$ & $1(1.4 \%)$ & $0(0.0 \%)$ & \\
\hline Hospitalization & $39(44.8 \%)$ & $30(42.3)$ & $12(52.2 \%)$ & \\
\hline
\end{tabular}

Data are shown as n (\%). ${ }^{*}$ Chi-square test

rate was found to be $14.5 \%$ in the population under 65 years of age and $44.8 \%$ in the group over 65 years of age.The most frequent reason for hospitalization in the group under and/or over 65 years of age was due to the cardiac origin. The overall ACS rate of these patients was $12.7 \%$. When we look at the literature, our current hospitalization rates are similar, but we have a higher rate of ACS. If we examine the causes of this situation, it was thought that the patients did not comply with hypertension (HT), hyperlipidemia, and Diabetes Mellitus (DM) treatments and did not have enough information about their health. It was thought that there was a moderate inverse relationship between the development level of the society and the incidence of ACS.

In a study conducted in our country regarding the age groups of patients with chest pain, it was observed that the age group under 65 years was higher. In this study conducted by Coşkun et al. [11], 76.4\% of the patients were under 65 years of age while $23.6 \%$ were over 65 years of age. In a study by Madsen et al. [12], it was found that $21.6 \%$ of the patients admitted to the emergency department with chest pain were patients over 65 years old while $78.4 \%$ were patients under 65 years old. In our study, $81.9 \%$ of the patients were under the age of 65 and $18.1 \%$ were over the age of 65 , which was consistent with the literature. As seen in these studies, the majority of the patients admitted to the emergency department with chest pain are patients under 65. That the individuals in the patient group under 65 years of age are socially active and they work actively can cause acute pain such as nonspecific myalgia. Because of the high life expectancy and increasing health literacy in the population under 65 years of age, patients pay attention to their complaints and apply to the emergency department. 
However, the clinical presentation is more prominent in patients with chest pain such as ACS. Pain localization is more specific in these patients as neuropathy is undeveloped or negligible. Because of the development of autonomic neuropathy and diabetic neuropathy in the group over 65 years, these patients apply to the emergency department less or later. Atypical findings are more common in the clinical presentation of these patients. In addition, the presence of comorbiditiesor previous ACS in patients over 65 years of age may mask patients' acute symptoms. This may reduce or delay the patient and patient relatives' paying attention to the condition. For instance, in a patient with chronic obstructive pulmonary disease (COPD), sudden onset dyspnea is perceived as COPD exacerbation by the patient and relatives, sometimes even by the clinician and the possibility of pulmonary embolism or acute heart failure may be missed. This delays the application and sometimes results in mortality. Elderly patients have difficulty in expressing themselves because of impaired cognitive functions. For this reason, the anamnesis that we recieve from the relatives of the elderly patients who know them is very important.

Advanced age is one of the causes of poor prognosis for ACS. Mortality in ACS increases by $70 \%$ with a 10 -year increase in age [13]. Although elderly people are at high risk and therefore constitute the group of patients who will benefit most from intensive treatment, they are treated with lower intensity and conservative methods in practice. $\mathrm{ACC} / \mathrm{AHA}$ is defined as an especially high risk group $>75$ years in the ACS treatment guidelines $[14,15]$.

In our study, the mortality rate was higher in the group over 65 years than in the group under 65 years. The mortality rate in patients with chest pain over 65 years is $1.1 \%$. When we look at the overall rate of our study, it was seen that the mortality rate was low compared to the general patient group. This rate is thought to be low due to the success of early diagnosis and treatment.

In a study conducted by Coşkun et al. [11], it was reported that the most common accompanying disease in patients admitted to the emergency department with chest pain was HT (33.3\%), the second was Coronary Artery Disease (CAD) $(26.8 \%)$ and the third was DM (13.6\%). In our study, the most common accompanyingdisease was HT (10-8\%), the second was $\mathrm{CAD}(9.9 \%)$ and the third was DM (7.7\%), which was consistent with the studies conducted in our country.

In a study conducted on the symptoms accompanying chest pain, it was found that $9.2 \%$ of patients had nausea-vomiting, 9.2\% had back pain, $9.2 \%$ had syncope, and $9.2 \%$ had shortness of breath [16]. The most common concomitant symptom was dyspnea in both age groups in our study. The reason for this might be that chest pain often causes shortness of breath.

I n our study, it was observed that the discharge rate of patients with chest pain under 65 was higher $(84.7 \%)$, whereas discharge rate was lower in the group over 65 years of age, but the hospitalization $(44.8 \%)$ or referral $(29.3 \%)$ rate was higher. It can be concluded from those findings that there is a more serious diagnosis in patients with chest pain over 65 and they should receive inpatient treatment.

Mortality and morbidity are higher in patients over 65 years of age as a result of changes in cardiovascular system and decrease in compensation mechanisms with age. Therefore, although the discharge rate is lower in the group over 65 years, the rate of referral to another institution for hospitalization or further treatment is higher.

\section{CONCLUSION}

In conclusion, it is seen that the demographic characteristics, vital signs, examination findings and physiological changes associated with aging are important in determining the causes of chest pain. Nowadays, with the increasing population, it is thought that the number of admissions of elderly patients to the emergency services will increase. Therefore physiological changes in these patients should be well known and these patients should beevaluated more carefully in terms of vital signs, additional symptoms and accompanying diseases.

\section{Conflict of interest}

The authors disclosed no conflict of interest during the preparation or publication of this manuscript.

\section{Financing}

The authors disclosed that they did not receive any grant during conduction or writing of this study. 


\section{REFERENCES}

1. Brown JB. Chest Pain. In: Marx JA, editor. Rosen's Emergency Medicine: Concepts and Clinical Practice. 8th ed. Philadelphia: Saunders; 2014: pp. 214-22.

2. Task Force for Diagnosis and Treatment of Non-ST-Segment Elevation Acute Coronary Syndromes of European Society of Cardiology, Bassand J-P, Hamm CW, Ardissino D, Boersma E, Budaj A, Fernández-Avilés F, et al. Guidelines for the diagnosis and treatment of non-ST-segment elevation acute coronary syndromes. Eur Heart J 2007;28:1598-660.

3. Swap CJ, Nagurney JT. Value and limitations of chest pain history in the evaluation of patients with suspected acute coronary syndromes. JAMA 2005;294:2623-9.

4. Six AJ, Cullen L, Backus BE, Greenslade J, Parsonage W, Aldous S, et al. The HEART score for the assessment of patients with chest pain in the emergency department: a multinational validation study. Crit Pathw Cardiol 2013;12:121-6.

5. Ruigomez A, Rodriguez LA, Wallander MA, Johansson S, Jones R. Chest pain in general practice: incidence, comorbidity and mortality. Fam Pract 2006;23:167-74.

6. Roger VL, Go AS, Lloyd-Jones DM, Benjamin EJ, Berry JD, Borden WB, et al; American Heart Association Statistics Committee and Stroke Statistics Subcommittee. Heart disease and stroke statistics--2012 update: a report from the American Heart Association. Circulation. 2012;125:e2-e220.

7. Lee TH, Goldman L. Evaluation of the patient with acute chest pain. N Eng J Med 2000;342:1187-95.

8. Goodacre S, Cross E, Arnold J, Angelini K, Capewell S, Nicholl J. The health care burden of acute chest pain. Heart 2005;91:229-30.

9. Pope JH, Aufderheide TP, Ruthazer R, Woolard RH, Feldman JA, Beshansky JR, et al. Missed diagnoses of acute cardiac ischemia in the emergency department. $N$ Eng $\mathrm{J}$ Med 2000;342:1163-70.

10. Roger VL, Go AS, Lloyd-Jones DM, Adams RJ, Berry JD, Brown TM, et al. Heart disease and stroke statistics-2011 update: a report from the American Heart Association. Circulation 2011;123:e18-e209.

11. Coşkun SÖ, Parlak I, Değerli V, Elçin G, Denizlioğlu B, Yildırım E, et al. [Evaluating the acute coronary sendrom rates of the patients who apply to emergency service with chest pain]. İzmir Eğitim ve Araştırma Hastanesi Tıp Dergisi 2015;19:8494.[Article in Turkish]

12. Madsen TE, Fuller M, Hartsell S, Hamilton D, Bledsoe J. Prospective evaluation of outcomes among geriatric chest pain patients in an ED observation unit. Am J Emerg Med 2016;34:207-11.

13. Granger CB, Goldberg RJ, Dabbous O, Pieper KS, Eagle KA, Cannon CP, et al. Predictors of hospital mortality in the global registry of acute coronary events. Arch Intern Med 2003; 163:2345-53.

14. Braunwald E, Antman EM, Beasley JW, Califf RM, Cheitlin MD, Hochman JS, et al.; American College of Cardiology, American Heart Association. Committee on the Management of Patients With Unstable Angina. ACC/AHA 2002 guideline update for the management of patients with unstable angina and nonST-segment elevation myocardial infarction-summary article: a report of the American College of Cardiology/American Heart Association task force on practice guidelines (Committee on the Management of Patients With Unstable Angina). J Am Coll Cardiol 2002;40:1366-74.

15. Antman EM, Anbe DT, Armstrong PW, Bates ER, Green LA, Hand M, et al. ACC/AHA guidelines for the management of patients with ST-elevation myocardial infarction; A report of the American College of Cardiology/American Heart Association Task Force on Practice Guidelines (Committee to Revise the 1999 Guidelines for the Management of patients with acute myocardial infarction). J Am Coll Cardiol 2004;44:E1-E211.

16. Orak M, Ustündağ M, Güloğlu C, Ozhasenekler A, Alyan O, Kale E. The role of the heart-type fatty acid binding protein in the early diagnosis of acute coronary syndrome and its comparison with troponin I and creatine kinase-MB isoform. Am J Emerg Med 2010;28:891-6. 